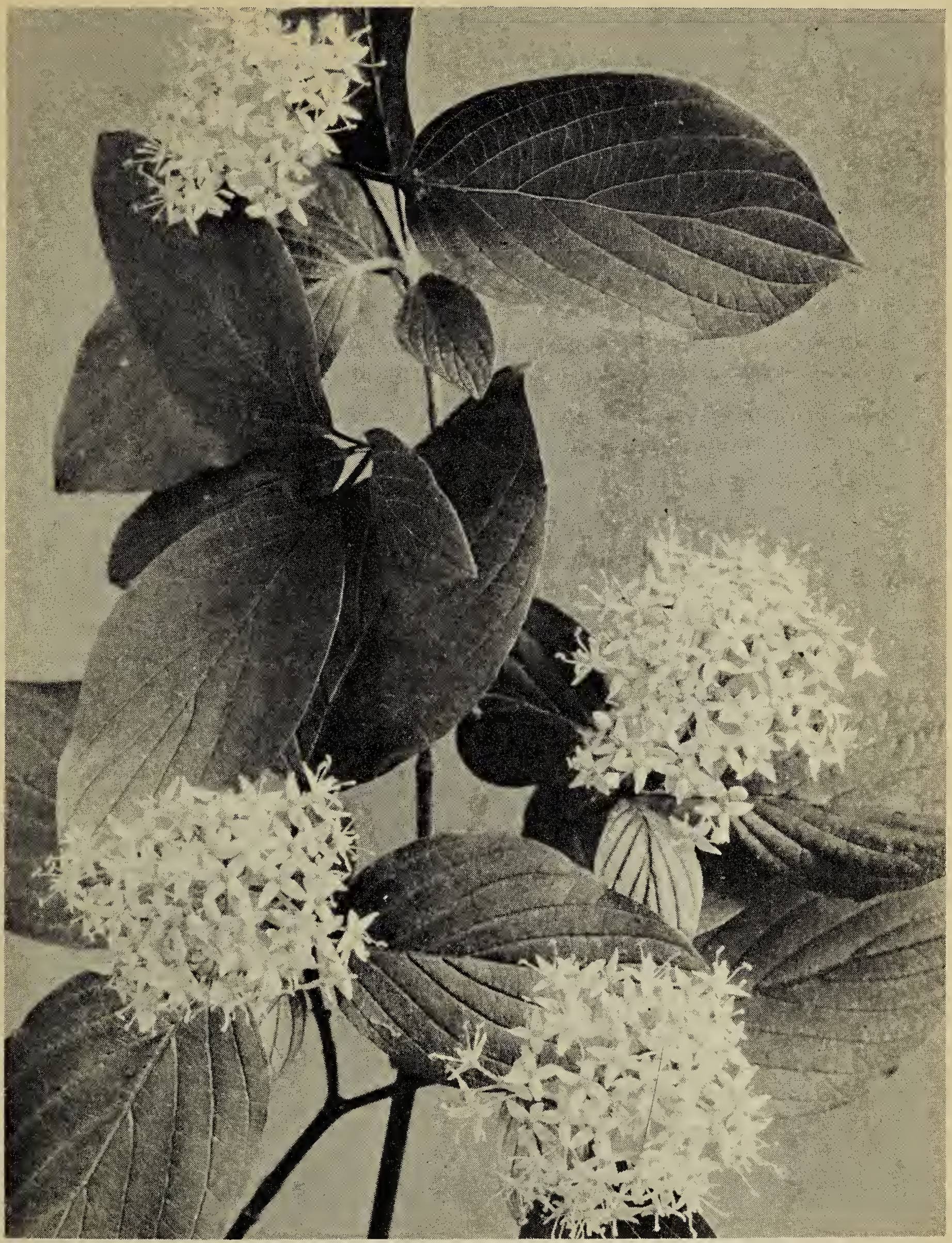

\title{
Red Osier Dogwood
}

Red Osier Dogwood, Cornus stolonifera Miahx.

Photo by W. C. McCalla

A common shrub that often adds to the beauty of our woods with its deep red twigs, its cluster of white flowers standing out against its beautiful leaves, and later, its white fruit, sometimes tinged blue. In winter its twigs add a touch of colour to a snowy landscape. 